\title{
THE DEVELOPMENT OF ROLLING TEXTURE IN $\propto$-BRASS DETERMINED BY NEUTRON DIFFRACTION
}

\author{
J. TOBISCH and A. MÜCKLICH $\dagger$ \\ Sektion Physik der Technischen Universität Dresden (GDR)
}

(Received February 20, 1973)

\begin{abstract}
The three-dimensional orientation distribution was calculated from neutron diffraction pole figures for a copper $27.2 \%$ zinc alloy cold rolled to different degrees of deformation. The results agree qualitatively with those of other authors. There are however differences in the quantitative respect which influence the conclusions to be drawn. For rolling degrees lower than about $70 \%$ the texture exhibits an orientation tube similar to that of the copper type, but with a significantly different distribution along the tube axis. For rolling degrees larger than $70 \%$ the texture can be described by the orientation $\{110\}\langle 112\rangle$. The deformation is assumed to occur according to the Wassermann model and the Hu model respectively in these two ranges.
\end{abstract}

\section{INTRODUCTION}

One of the most intensively studied problems in texture research is the development of rolling textures in f.c.c. metals and alloys. Upon rolling these materials develop one or the other of two types of textures, the change between them being brought about either by alloying or by changing the rolling temperature. There is no doubt that the change in the textures must be due to a corresponding change in the deformation mechanisms. Hence texture investigations offer themselves a good means to study the deformation mechanisms underlying polycrystal plasticity. Generally it is assumed that the change from the copper type to the brass type is somehow connected with decreasing stacking fault energy. There is, however, some divergence of opinion as to which specific mechanism is really responsible. Among the various mechanisms, for example, deformation twinning ${ }^{1}$, cross $\operatorname{slip}^{2,3}$ a dislocation interaction ${ }^{4}$, and deformation faulting ${ }^{5}$ have been suggested.

In order to prove or disprove the different models, their outcomes must be compared quantitatively with experimentally determined textures. This is most effectively done with the help of the threedimensional orientation function because of its unequivocality with respect to crystal orientations. Using this representation the texture development in the copper-zinc system has been studied recently

$†$ Zur Zeit Zentral institut für Kernforschung Rossendorf, Akademie der Wissenschaften der DDR (GDR). by different authors ${ }^{6,7,8}$. In general the results of the various studies are similar, there are, however, some deviations in the quantitative respect which influence the conclusions drawn from them, and which consequently require further investigations. Thus the rolling texture of copper was found to consist of a tube of preferred oreintations running from $\{110\}\langle 112\rangle$ to a high index oreientation between $\{112\}\langle 111\rangle$ and $\left\{\begin{array}{lll}4 & 4 & 11\end{array}\right\}\left\langle\begin{array}{llll}11 & 11 & 8\end{array}\right\rangle^{6}$. The orientation density measured along the central line of this tube increased from about 12 times the random density at the $\{110\}\langle 112\rangle$-end to about 15 at the other end for the $95 \%$ cold rolled texture. During rolling the severity of this texture component did not develop continuously, rather it passed through a minimum at $70 \%$ reduction. Kallend and Davies ${ }^{8}$ reinvestigated the rolling texture of copper, and found a very similar orientation tube. They did not, however, evaluate from their orientation distribution functions the density along the central line of the tube. Instead, they drew the density curve for a path running from $\{110\}$ $\langle 112\rangle$ to exactly $\left\{\begin{array}{lll}4 & 4 & 11\end{array}\right\}\left\langle\begin{array}{lll}11 & 11 & 8\end{array}\right\rangle$. But obviously this path leaves the central line of the tube by about 5 degrees which is enough to decrease the density from about 12 at the exact maximum position to about 8 at the $\left\{\begin{array}{lll}4 & 4 & 11\end{array}\right\}\left\langle\begin{array}{llll}11 & 11 & 8\end{array}\right\rangle$-position. This observation has led these authors to conclude that the density decreases along the tube in this direction. Furthermore, Kallend and Davies did not find a discontinuity at $70 \%$ reduction. Unfortunately, they did not give the oreintation distribu- 
tion functions for all the investigated rolling degrees. Neither did they present all the starting pole figures but only those of the (111)-plane. Hence one cannot decide whether there is a real deviation with respect to our previous findings, or it may be due to the different method used for evaluating the orientation density functions.

In the paper by Kallend and Davies, the texture development in a copper- $30 \% \mathrm{Zn}$ alloy was also studied. In this case a discontinuity was found in the pole figures at $80 \%$ reduction. (The intensity peak in the vicinity of the normal direction is markedly changed in this pole figure.) However, this discontinuity was not mentioned in the discussion of the results. If it is assumed that the discrepency is within the limit of error of the investigation, then this limit must have been fairly high. (Unfortunately, no quantities were given in their paper which allow the limit of reliability to be estimated.) Thus it may be justified to present here the results of an investigation on a very similar copper-zinc alloy which deviate in some quantitative respects from those by Kallend and Davies, thus leading to different conclusions as to the deformation modes in the early deformation stages.

\section{EXPERIMENTAL}

An alloy containing $27.2 \% \mathrm{Zn}$ was prepared from $99.5 \%$ purity starting materials. It was first forged, then hot rolled, and finally machined to form a slab of $1 \times 5 \times 30 \mathrm{~cm}$. This slab was cold rolled in a twohigh laboratory mill to reductions of $30,50,70,80$, 90,93 , and $95 \%$. The pole figure measurements were carried out by neutron diffraction because of the higher accuracy of this method compared with X-ray diffraction ${ }^{9}$. Specimens of $5 \times 5 \mathrm{~cm}$ were used so that the results represent the mean value of the texture over the whole strip width and thickness. The measurements were made in the way described earlier ${ }^{6,7}$ in steps of $6^{\circ} \times 6^{\circ}$. They were corrected for background scattering absorption and geometrical factors, and were reduced to multiples of the random density (mrd-units) by integrating over the whole pole figure.

\section{RESULTS}

In Figure 1 the normalized (111)-pole figures are shown for different degrees of reduction. They are similar to those by Kallend and Davies with the exception of that for $80 \%$ reduction. Along with (200), (220), and (311) pole figures they were used to calculate the three-dimensional orientation distribution functions ${ }^{10}$ shown in Figure 2. To facilitate a quantitative check of the results the coefficients $C_{\lambda}^{\mu \nu}$ of the series development are given in Table 1 in the Appendix. For all the rolling degrees the maximum orientation density occurs at an orientation A a few degrees apart from the "ideal brass orientation" $\{011\}\langle 211\rangle$. For the lower rolling degrees the orientation density is stretched out along an orientation tube similar to that observed formerly in cold rolled copper. That is to say it passes through a point $B$ between the low index orientation $\{112\}\langle 111\rangle$ and the theoretically predicted orientation $\left\{\begin{array}{lll}4 & 4 & 11\end{array}\right\}\left\langle\begin{array}{llll}11 & 11 & 8\end{array}\right\rangle^{11}$. Point $B$ is a saddle point of the orientation density function because its density is maximal measured in a section perpendicular to the axis of the orientation tube and it is minimal measured along this axis. For the higher rolling degrees there is no such tube. Only a certain spread range is to be observed, however, in a direction different from the original tube direction. A second spread range can be seen to occur for all rolling degrees. It is stretched out from point A towards point $\mathrm{C}=\{011\}\langle 100\rangle$.

It is not quite easy to imagine the features of a complex three-dimensional distribution function from looking only at planar sections of this function. such as the constant $-\varphi_{2}$-sections of Figure 2 . Therefore we drew the equidensity lines of the sections on plexiglas-slabs which were stacked one upon another the way shown in Figure 3. Because of the light reflection at the slab surfaces, however, it was necessary to illuminate the stack of slabs from underneath. This simple device proved very useful in representing three-dimensional density functions, and we often used it in the discussion of the features of texture functions. As is to be seen in Figure 3, however, a two-dimensional reproduction of the stack of slabs does not show the features of the function to be represented. Therefore perspective drawings were prepared which are shown in Figure 4 for $30 \%$ and $95 \%$ rolling reduction. Because of the complexity of the three-dimensional distribution function which would be too confusing in the two-dimensional perspective representation, only one of the different equidensity surfaces corresponding to half the maximum density is represented here. Hence the perspective drawing does not contain the full information about the three-dimensional distribution function. Nevertheless, it may come in useful in visualizing the topological connections of 
DEVELOPMENT OF ROLLING TEXTURE IN BRASS

213
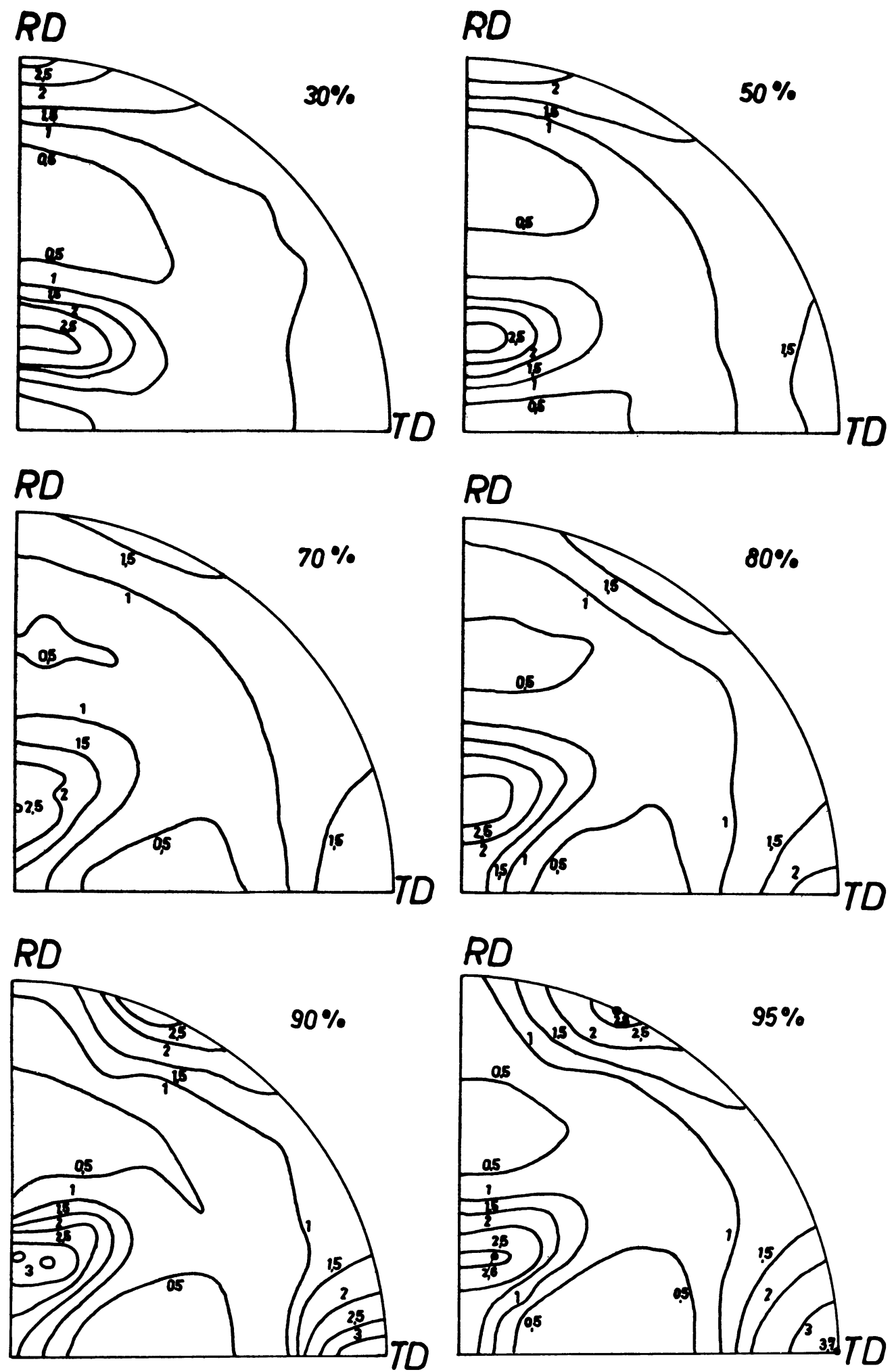

FIGURE 1 Normalized (111)-pole figures of $\alpha$-brass cold rolled to different degrees of reduction determined by neutron diffraction.

B 


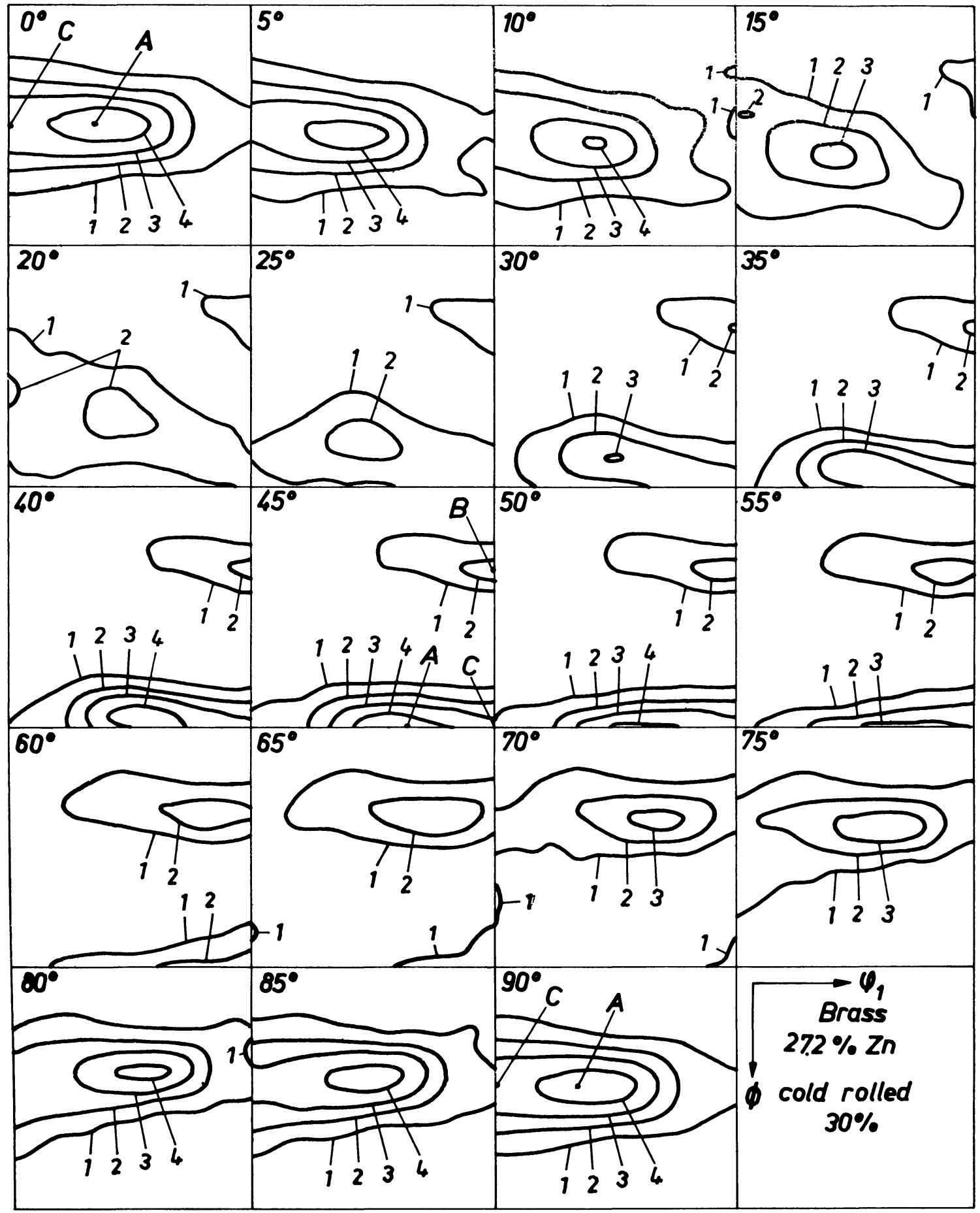

FIGURE 2(a)

FIGURE 2. Three-dimensional orientation distribution functions in multiples of the random distribution for $\alpha$-brass cold rolled to different degrees of deformation. 


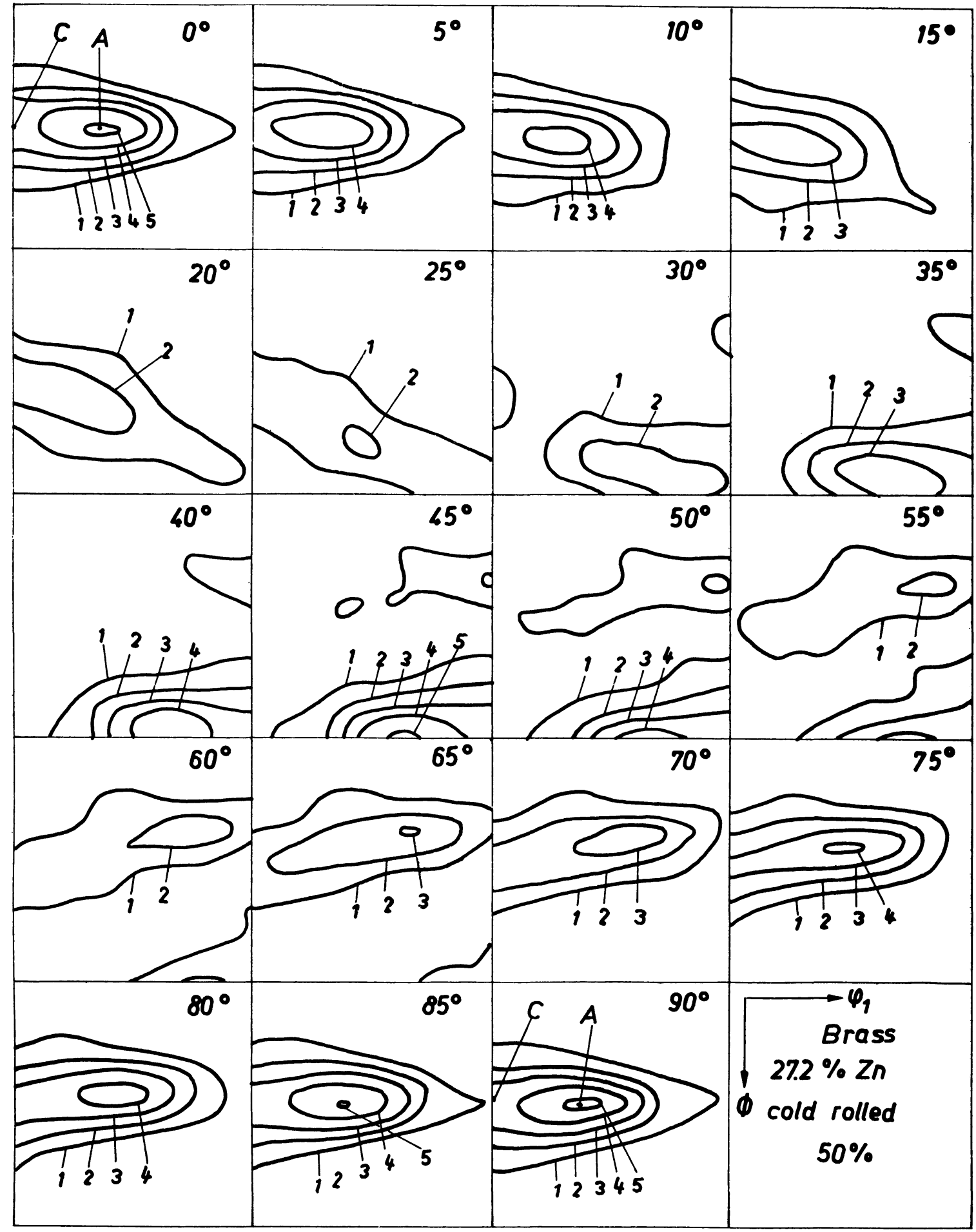

FIGURE 2(b) 
216

J. TOBISCH AND A. MÜCKLICH

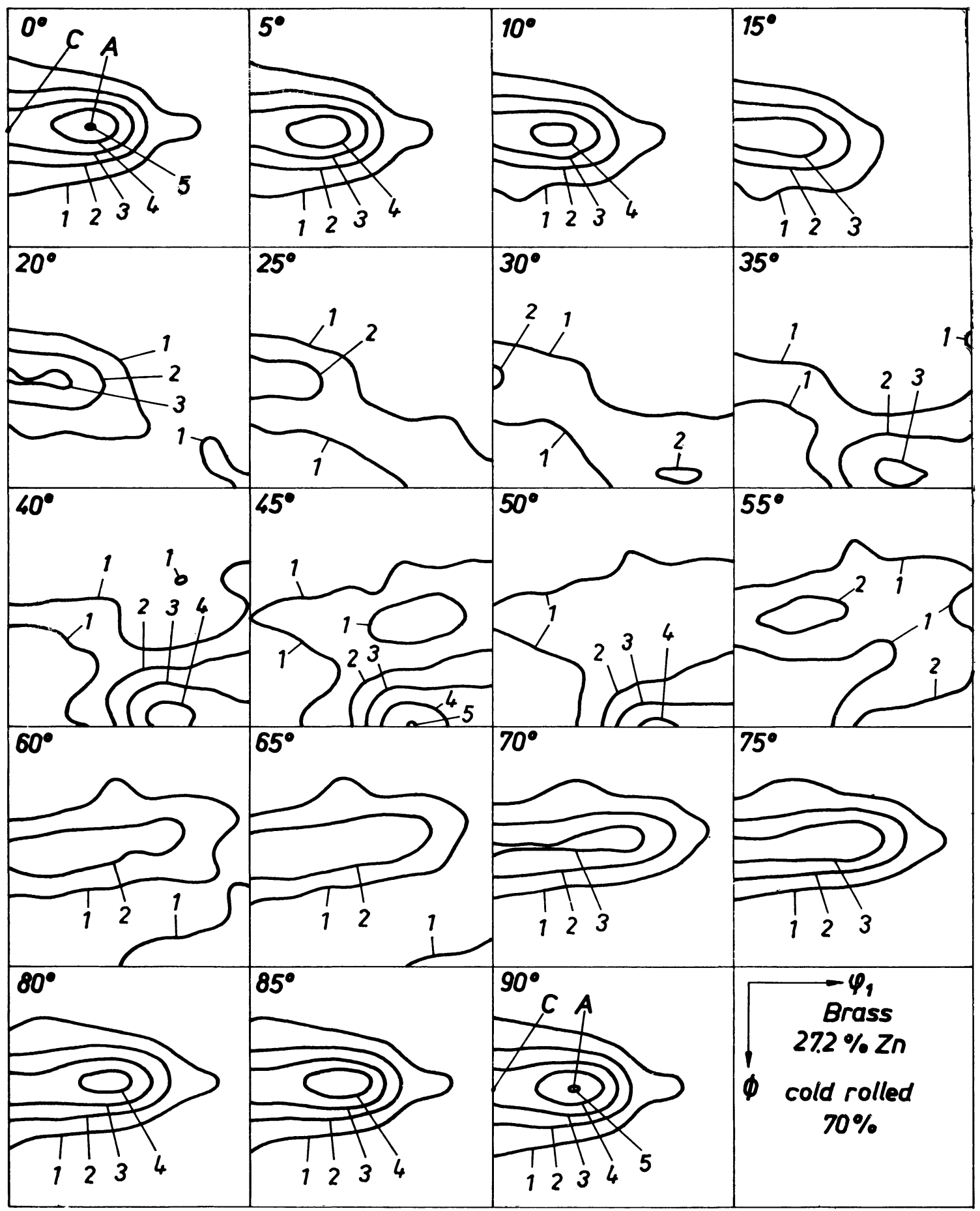

FIGURE 2(c) 


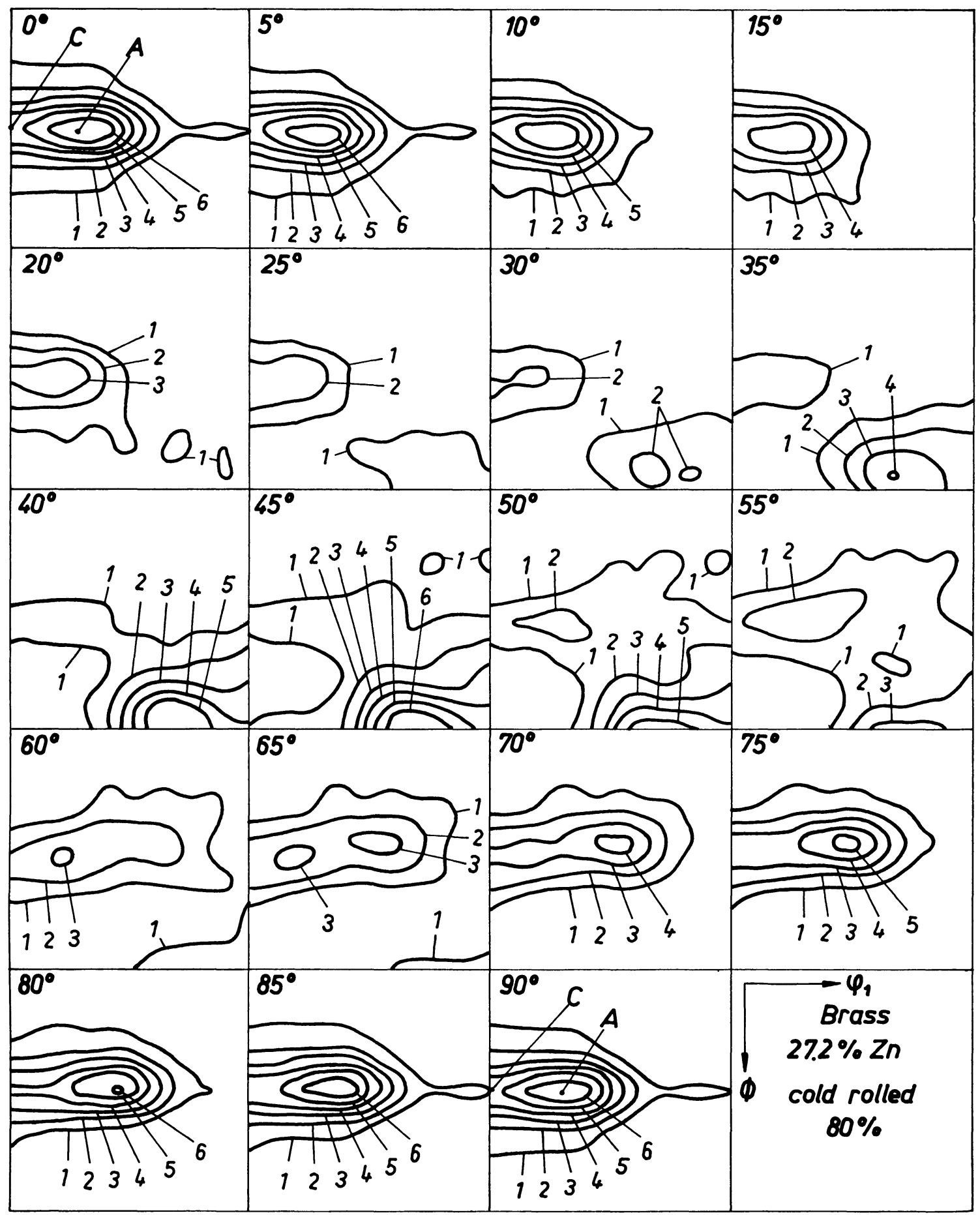

FIGURE 2(d) 


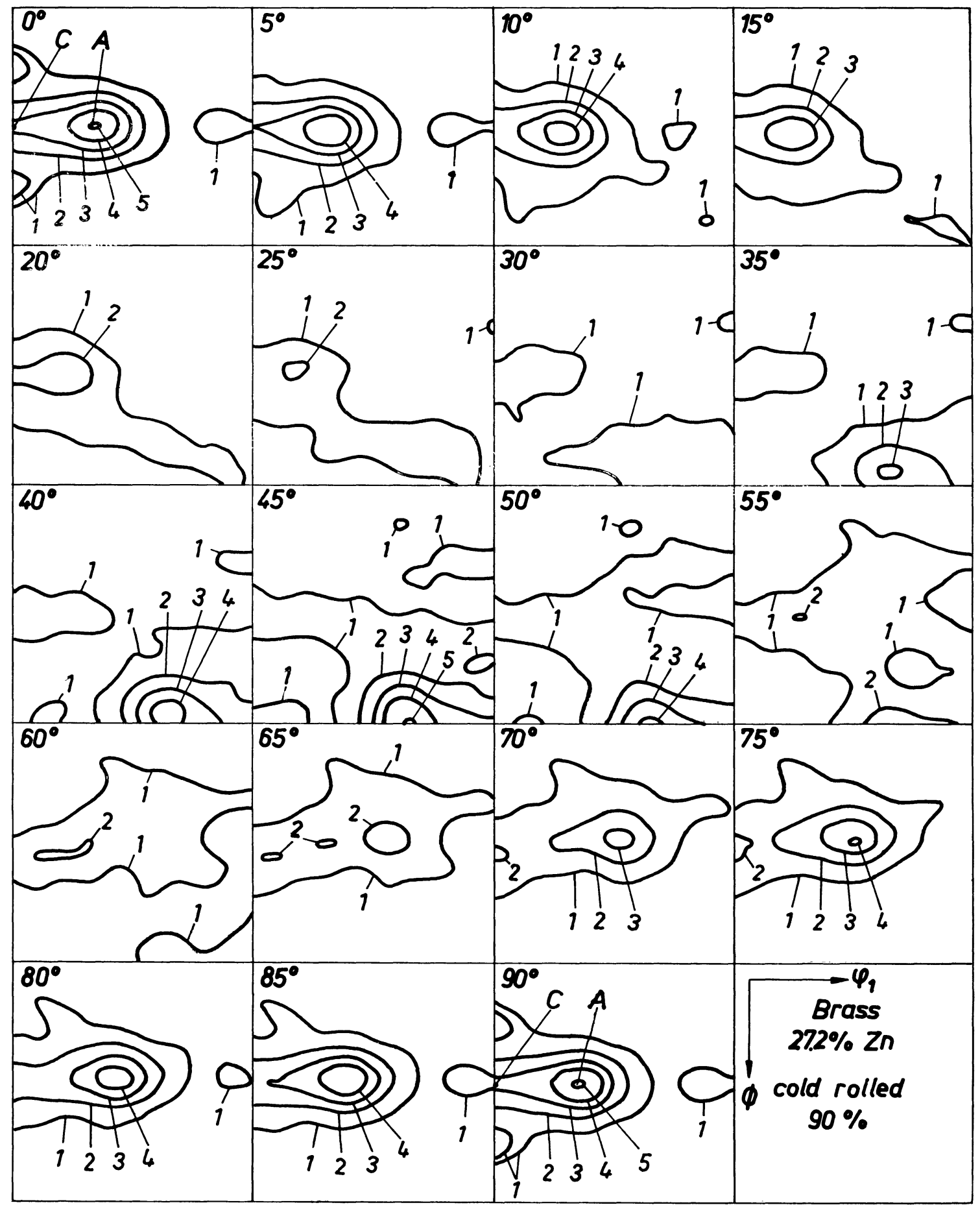

FIGURE 2(e) 


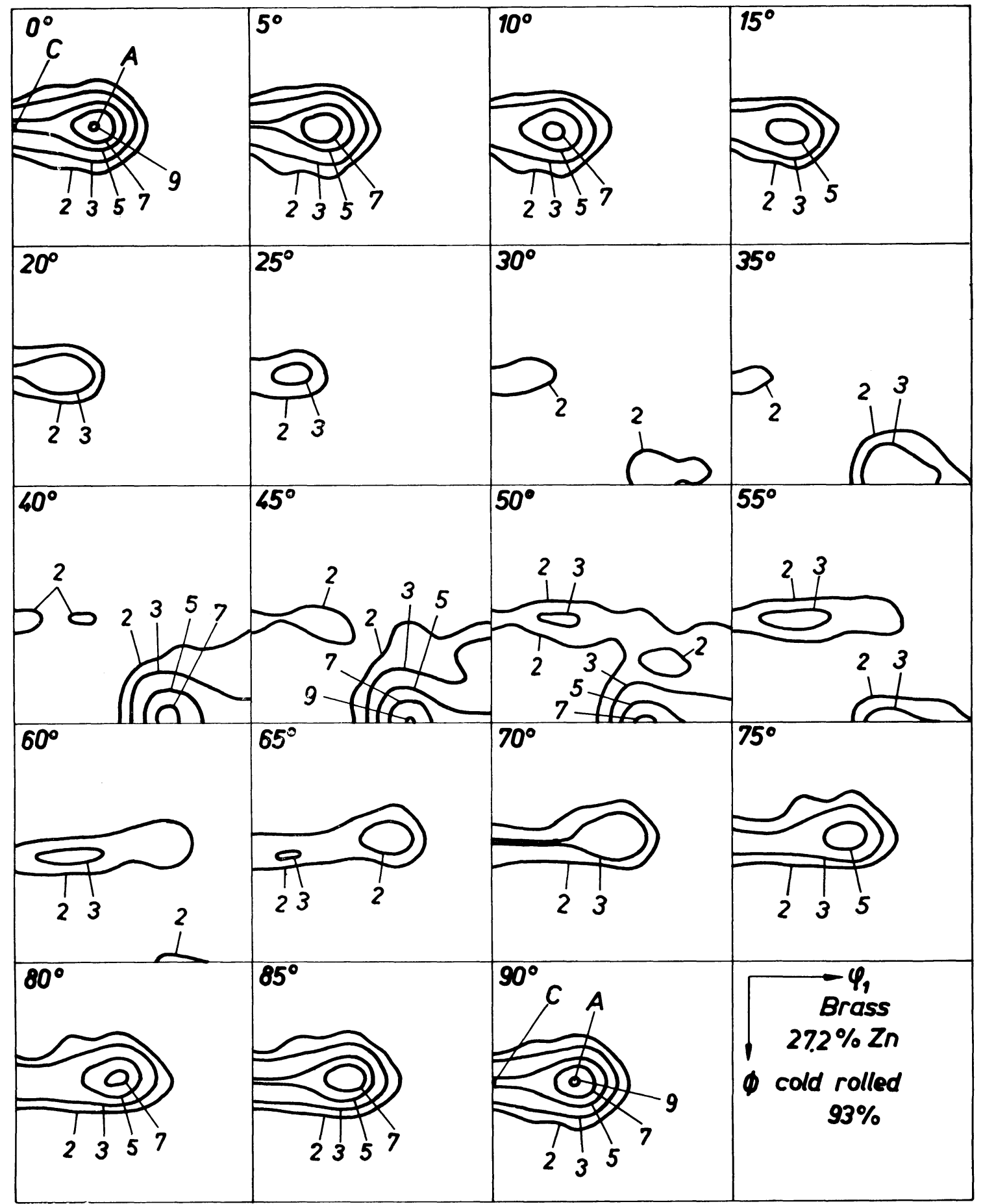

FIGURE 2(i) 


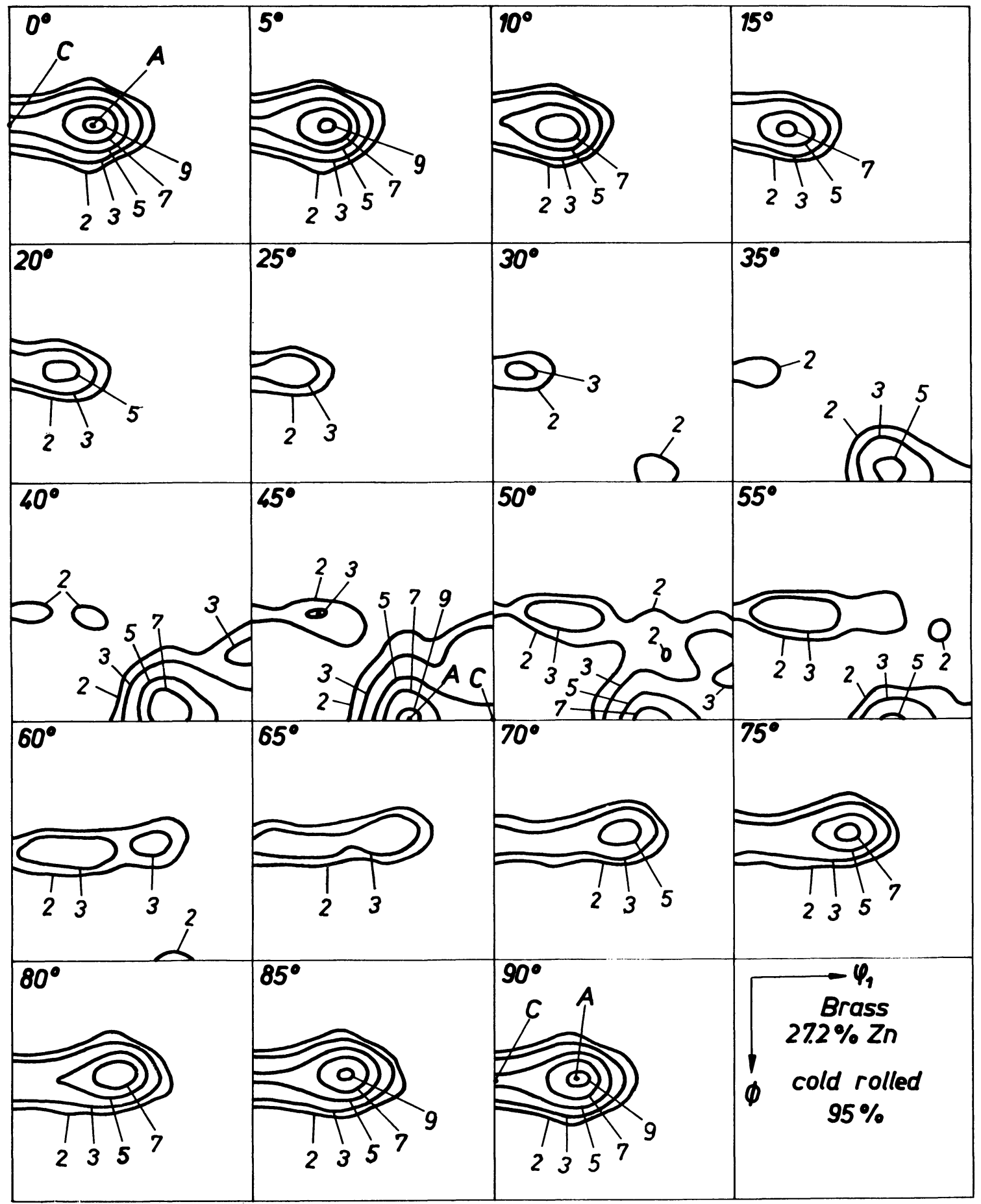

FIGURE 2(g) 


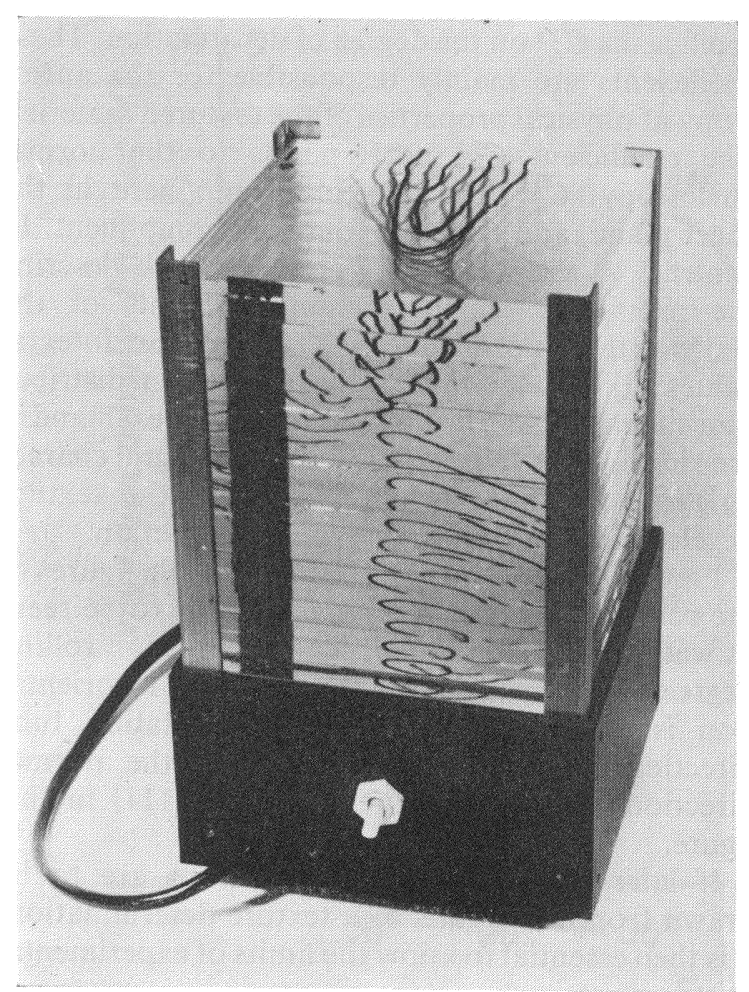

FIGURE 3 Plexi-glass model used for the representation of the orientation distribution function in the three-dimensional orientation space.

the different branches of spread in the threedimensional orientation space.

In Figure 5 the orientation density along the skeleton line $\mathrm{A}-\mathrm{B}$ of the tube component is shown. For the higher rolling degrees the line A-B does not coincide with the main spread range. Hence the corresponding curves in Figure 5 are not extended up to point $\mathrm{B}$. The dashed-line corresponding to pure copper cold rolled $30 \%$ was reproduced from a previous paper ${ }^{6}$. It shows that there is a significant difference between the rolling textures in the pure metal type and the alloy type respectively even at as low a rolling degree as $30 \%$. Figure 6 shows the orientation density along the second spread direction $\mathrm{A}-\mathrm{C}$. The texture development at the three main orientation points $\mathrm{ABC}$ during rolling is summarized in Figure 7 . It should be mentioned in this connection that of these three prominent points only point $\mathrm{C}$ is completely fixed by symmetry considerations whereas the maximum point $\mathrm{A}$ is of the general form $\{011\}\langle$ hII $\rangle$ and the saddle point $B$ is of the form $\{11 \mathrm{~h}\}\langle 111\rangle$. Hence either of the latter ones has one degree of freedom. Point B was found to deviate significantly from the low index orientation $\{112\}\langle 111\rangle$ and very probably also from $\left\{\begin{array}{lll}4 & 4 & 11\end{array}\right\}\left\langle\begin{array}{llll}11 & 11 & 8\rangle \text {, whereas point } A \text { was }\end{array}\right.$ very near but not exactly at $\{011\}\langle 211\rangle$, the deviation being, however, within the limit of error. Because of these reasons it must be considered more adequate to describe the texture in terms of these extremum points of the distribution function rather than by certain low index points. Curve A should be exactly comparable with the corresponding one by Kallend and Davies which is shown as a dashed line in Figure 7. For the lower rolling degrees the two curves coincide within the limit of error. For the higher ones, however, the values of curve $\mathrm{A}$ are about $40 \%$ larger than those of the dashed-line curve. We shall comment on this deviation later when discussing the possible sources of error.

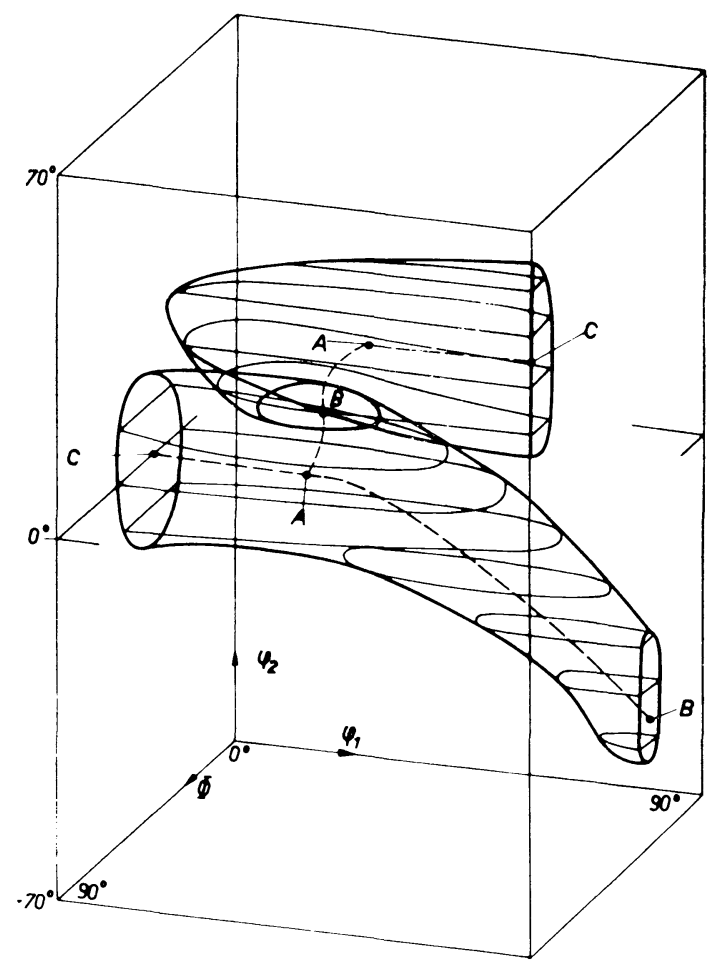

FIGURE 4(a)

FIGURE 4 Perspective representation of the half-maximum surface of the orientation distribution function of $\alpha$-brass cold rolled (a) $30 \%$ and (b) $95 \%$. The dashed lines are the skeleton lines of the two orientation tubes A-B and A-C respectively. 


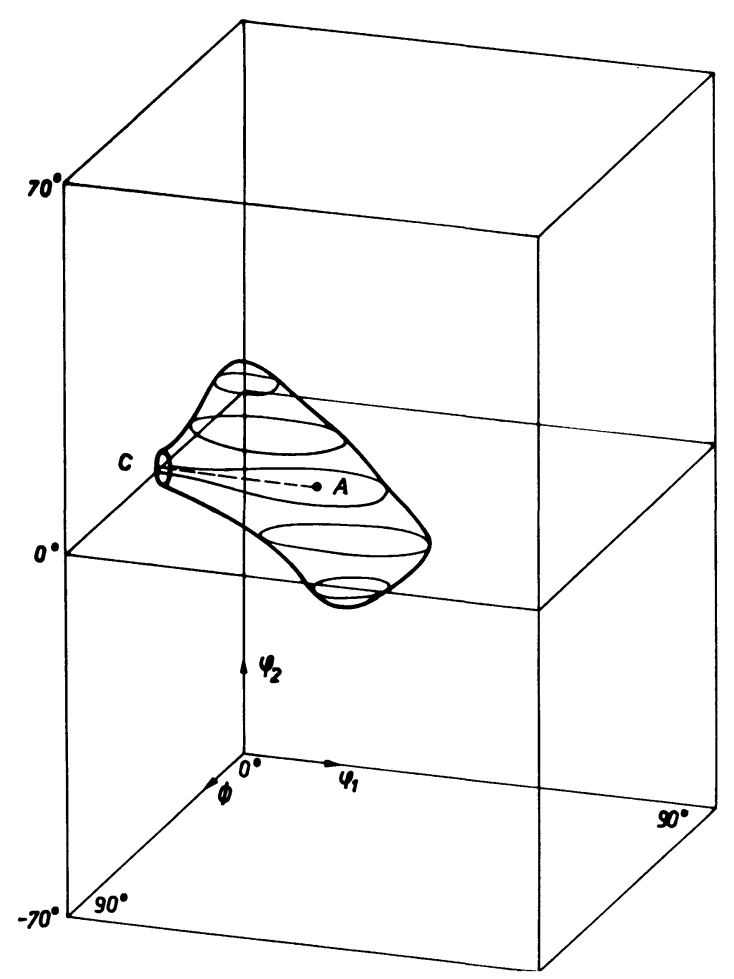

Figure 8 shows the dependence of the fourth order coefficients $C_{4}^{1 v}$ on the degree of deformation. These coefficients are mainly responsible for the anisotropy of physical properties of the textured material. The coefficient $C_{4}^{11}$ corresponds to the normal anisotropy, $C_{4}^{12}$, the two-fold component in the sheet plane, and $C_{4}^{13}$, the four-fold component. In contrast to the values of Figure 7 which describe the prominent single orientation points of the textures these coefficients are the simplest integral values taken over the whole orientation distribution function. As is to be seen in Figures 7 and 8 the single point values as well as the integral characteristics indicate a certain change in the texture development at about $70 \%$ rolling reduction.

Figure 9 shows some of the inverse pole figures of the rolling and normal directions. It is to be seen, as was already mentioned, that for the high rolling degrees the spread about the $\{011\}\langle 211\rangle$-orientation is not along the original orientation tube direction, that is, towards $\{112\}$ in the normal direction figure, but rather, towards $\{111\}$ in this figure.

If later on quantitative conclusions are to be drawn from the results of a texture determination, it is then essential to know the limits of experimental

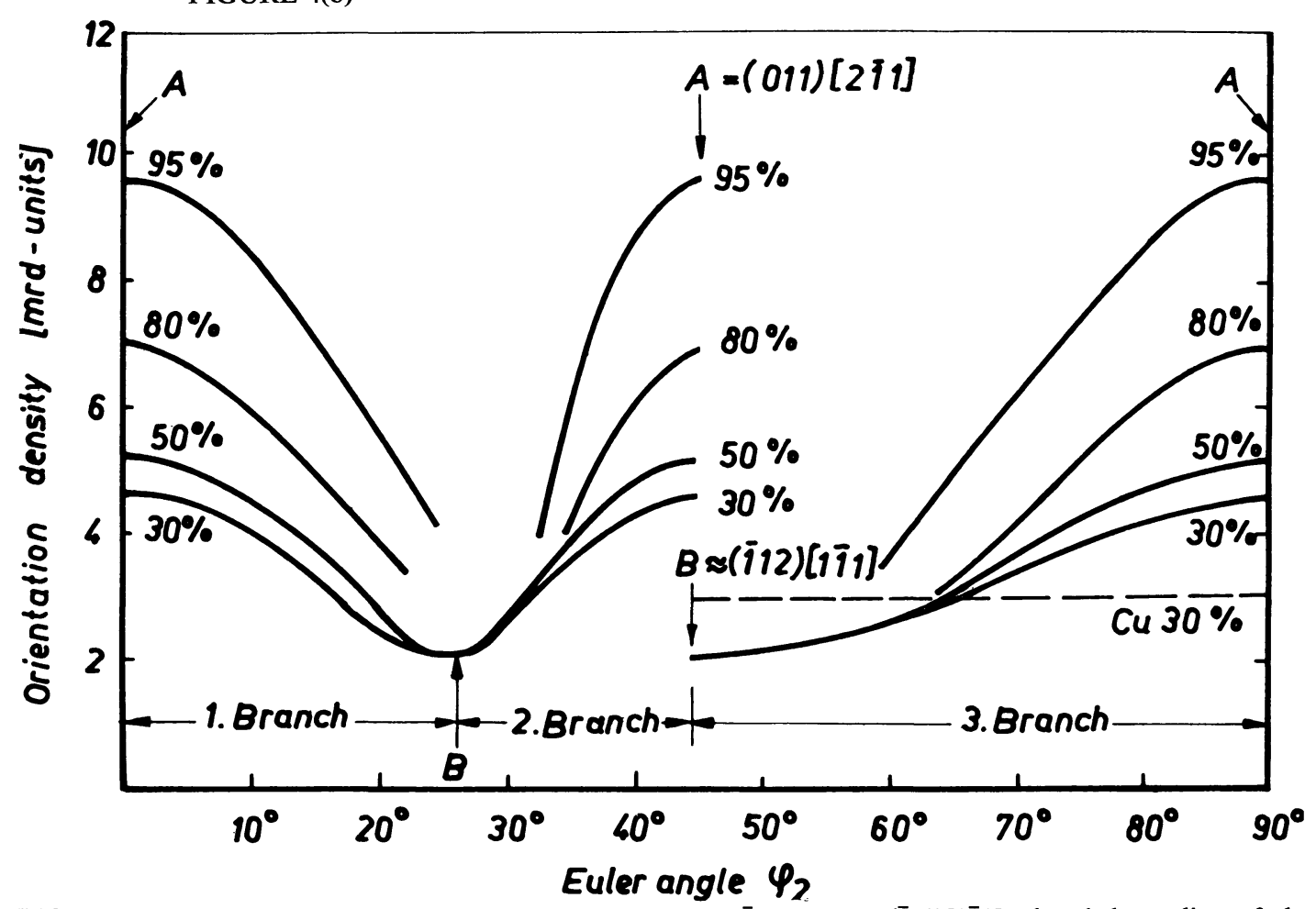

FIGURE 5 Orientation density along the path $A=(011)[2 \overline{1} 1]$ to $B \approx(112)[1 \overline{1} 1]$, the skeleton line of the orientation tube of the low rolling degree textures. The dashed line corresponds to copper cold rolled $30 \%{ }^{6}$. 


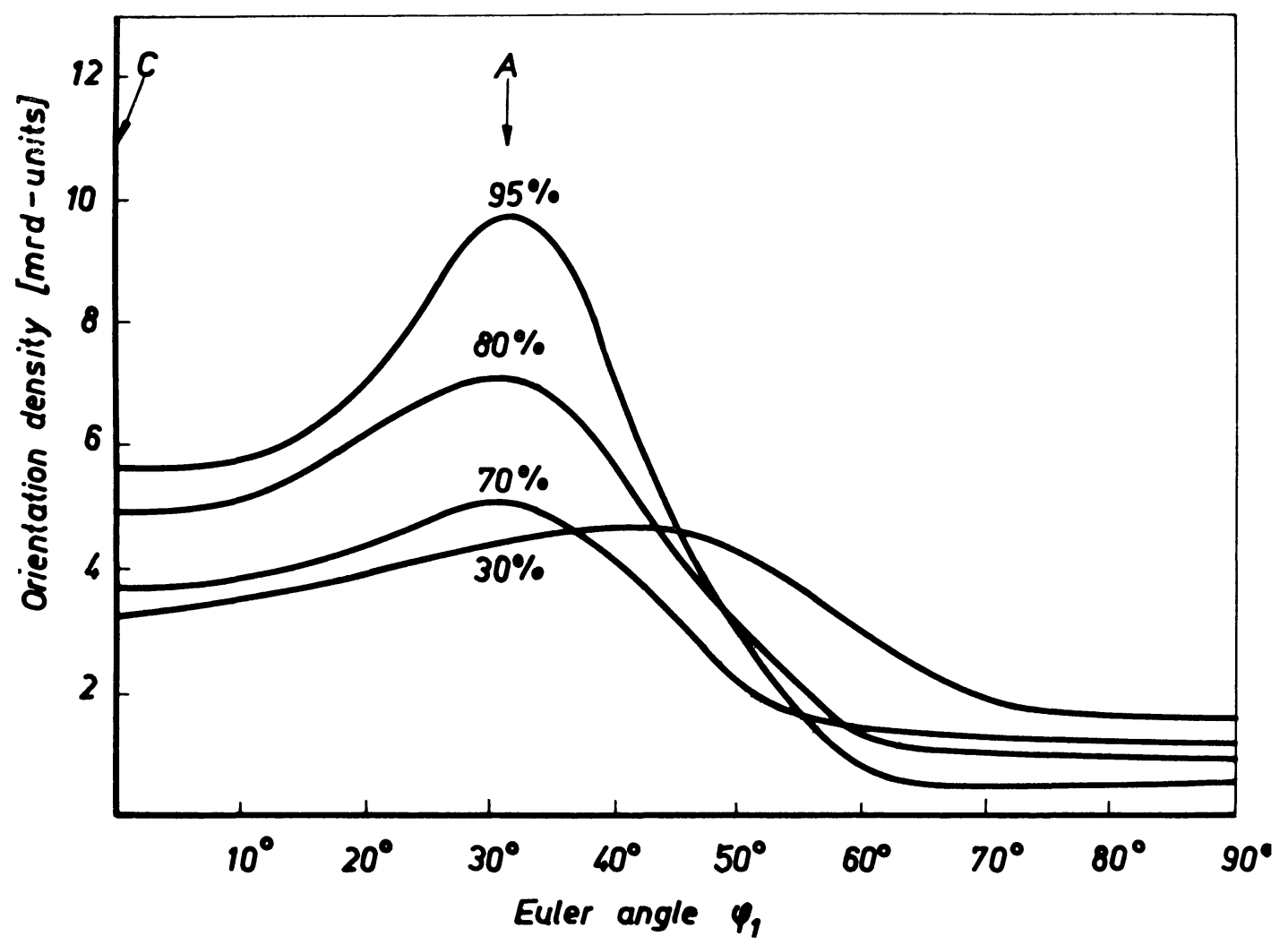

FIGURE 6 Orientation density along the path $A=(011)[2 \overline{1} 1]$ to $C=(011)[100]$.

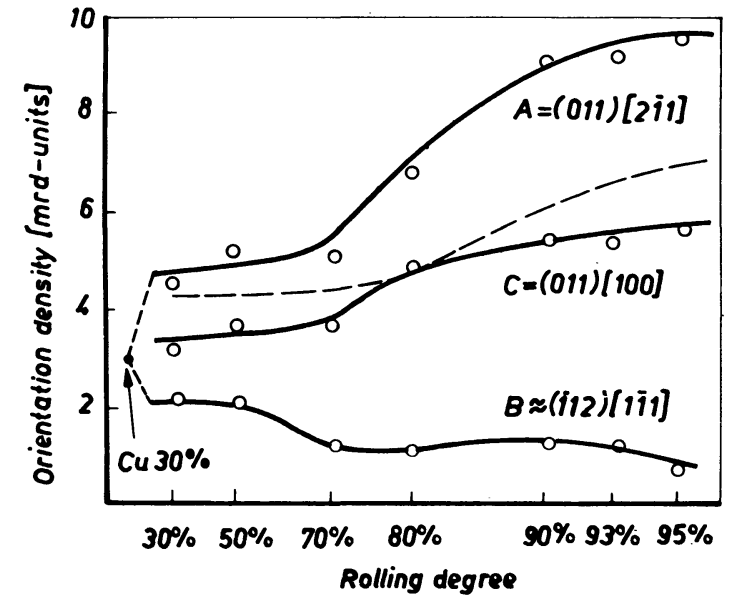

FIGURE 7 Orientation density at the three prominent points of the orientation distribution as a function of the rolling degree. The dashed-line curve corresponds to the orientation $\boldsymbol{A}$ determined by Kallend and Davies ${ }^{8}$.

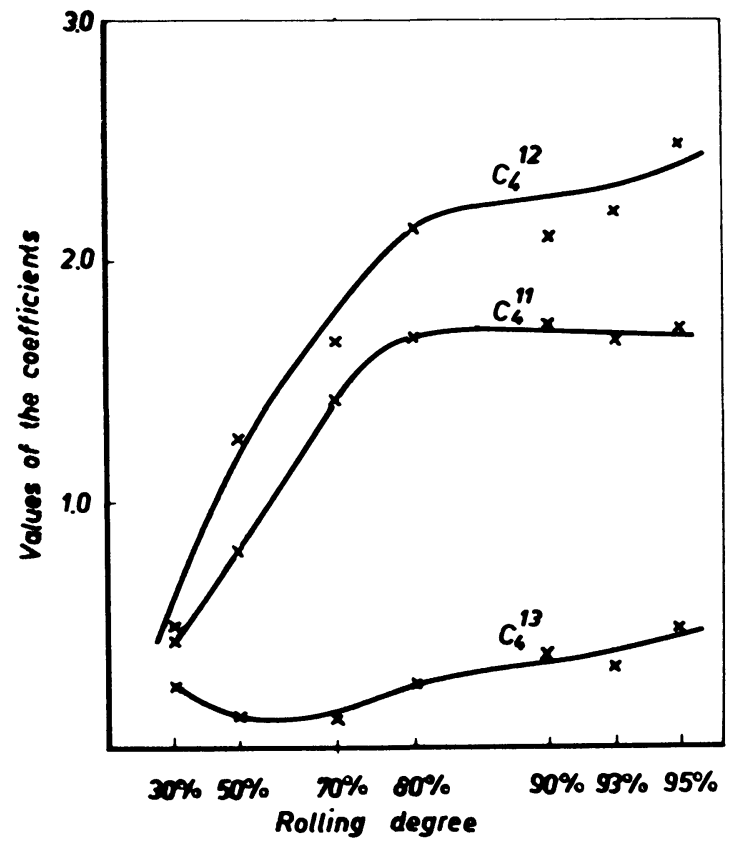

FIGURE 8 The first three coefficients $C_{4}^{1 v}$ of the series development as a function of the rolling degree. 

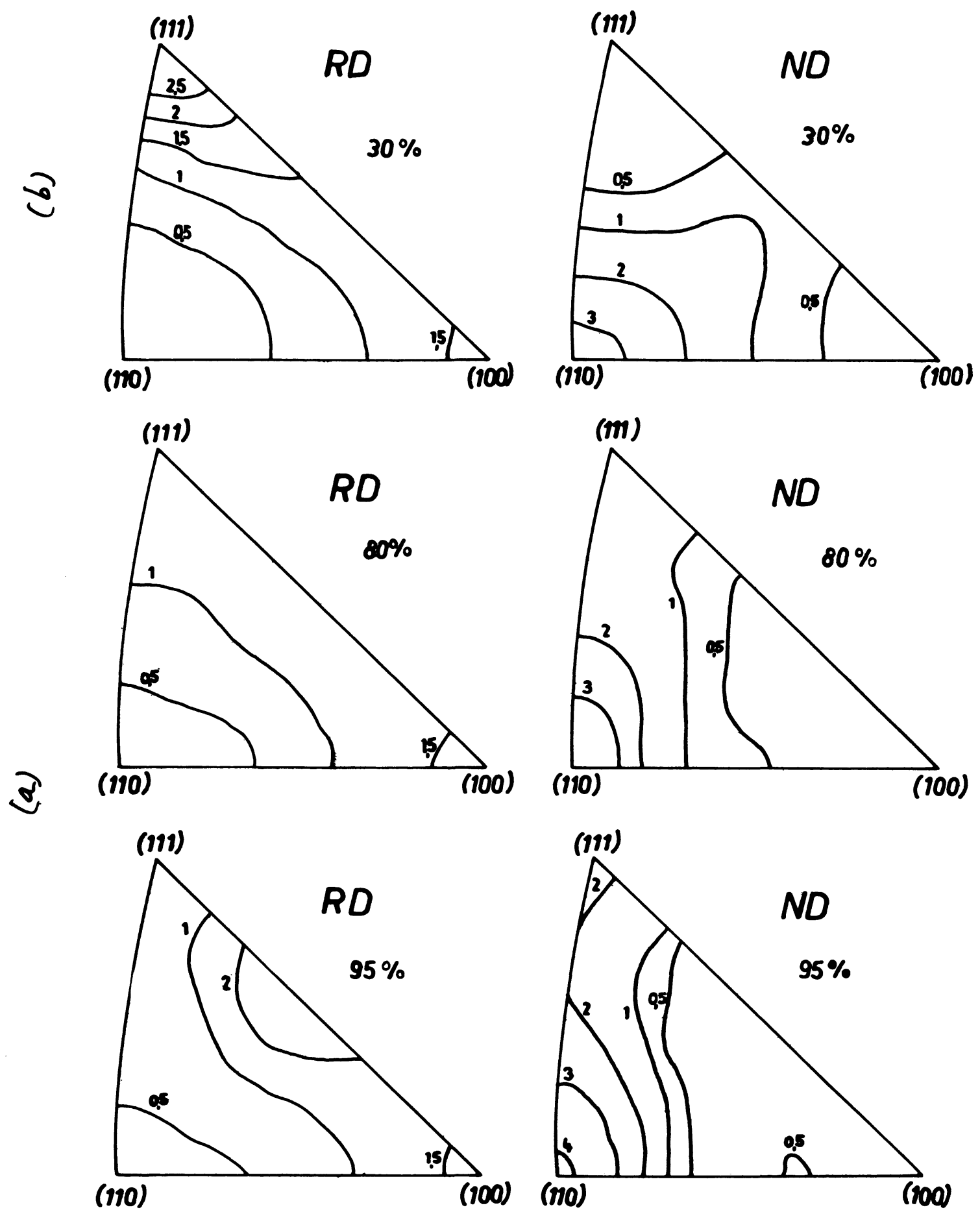

FIGURE 9 Inverse pole figures for rolling and normal direction at various degrees of deformation. 
and computational errors. An estimation of the errors can be obtained in several different ways. For example, the errors of the coefficients $C_{\lambda}^{\mu v}$ can be estimated because these coefficients have been calculated by solving over-determined systems of linear equations. Hence the errors of the coefficients $C_{\lambda}^{\mu \nu}$ may be regarded as measures of the compatibility of the different pole figures. In Figure 10 the mean values of the coefficients $C_{\lambda}^{\mu \nu}$ (taken over $\mu$ and $v$ ) are shown along with the corresponding errors. It is to be seen that for $\lambda=$ 22 the coefficients have not yet completely decreased to the level of error. Thus in addition to the experimental error the results are inflicted by a certain amount of computational error due to the series truncation. Kallend and Davies in their paper stated that the coefficients had decreased to the level of error at $\lambda=20$. Hence it must be concluded that in their case the errors were larger. This must be

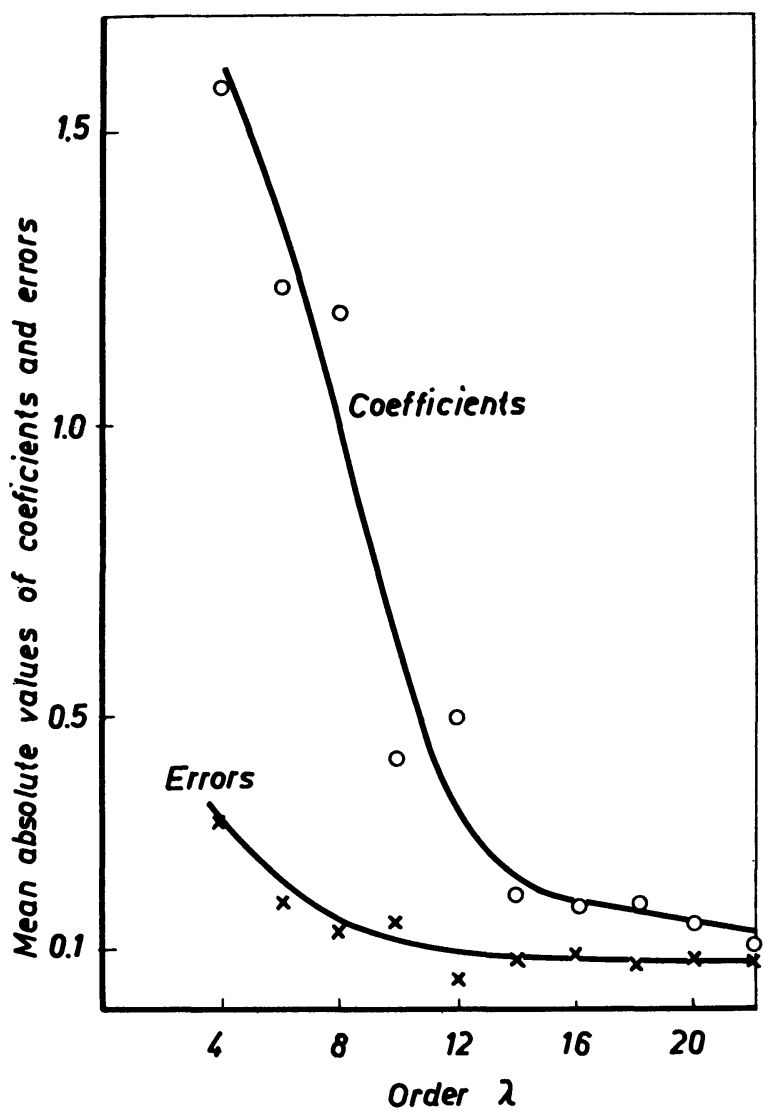

FIGURE 10 The mean absolute values of the coefficients $C_{\lambda}^{\mu_{\nu}}$ and their probable errors $\Delta C_{\lambda}^{\mu_{\nu}}$ as a function of the order $\lambda$ for the $95 \%$ cold rolled texture. taken into account when later on discussing the results. According to the generalized Harris relation 10,12 the density value of the inverse pole figure corresponding to the specimen direction $\vec{y}$ (for example normal or rolling direction) taken at the crystal direction $\langle\mathrm{hkl}\rangle$ should be equal to the value of the (hkl)-pole figure taken at the specimen direction $\vec{y}$

$$
I_{y}(h k l)=P_{h k l}(y) .
$$

In this relation the pole figure values are experimental values corresponding to one single point of one single pole figure. On the other hand the inverse pole figure values are calculated via the coefficients $C_{\lambda}^{\mu \nu}$ taking into account all the points of all the experimentally determined pole figures. They must be inflicted by the full experimental error, including the incompatibility error of the pole figures as well as the truncational error. Hence the generalized Harris relation provides a good means to estimate the reliability of a texture determination. In Figure 11 this relation is proved for two orientations, namely $\{111\}$ parallel to the rolling direction and the transverse direction. The values were taken

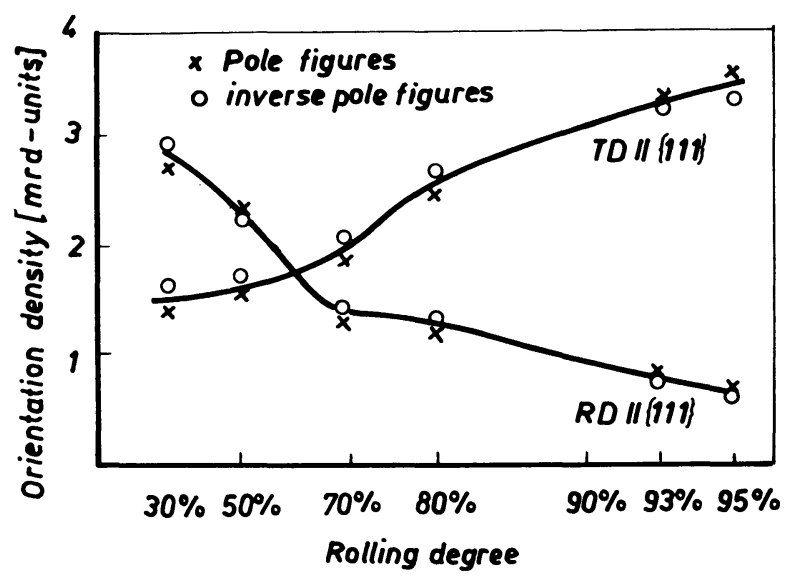

FIGURE 11 Orientation density at corresponding points of the pole figures and inverse pole figures illustrating the validity of the generalized Harris relation.

from the inverse pole figures of the rolling and the transverse directions and from the (111)-pole figures. The agreement between the two corresponding values is fairly good thus indicating the reliability of the calculated orientation density values. The deviation is in the order of magnitude of about $9 \%$ for the $95 \%$ texture. Hence the deviation of more than $40 \%$ of curve $\mathrm{A}$ in Figure 7 from the 
corresponding dashed-line curve must be regarded as beyond the limit of error of the present determination. On the other hand the (111)-pole figure of the present determination is very similar to the corresponding one by Kallend and Davies. Both these pole figures yield nearly the same maximum density values. Hence the deviation shown in Figure 7 must be due to either a larger truncational error or a larger incompatibility of the different pole figures. It is assumed that the latter is the most probable, because the composite sample method of pole figure determination described by Elias and Heckler ${ }^{13}$ and utilized by Kallend and Davies is very sensitive to even slight deviations in the specimen's alignment.

\section{DISCUSSION}

As was shown in the previous sections that for a quantitative texture investigation it is necessary to carefully analyse the probable errors of the results. A deviation of about $40 \%$ in the density values for very similar textures as shown in Figure 7 naturally will influence the conclusions to be drawn from these data.

The present results on the development of the rolling texture of $\alpha$-brass summarized in Figure 7 suggest that there are two deformation ranges corresponding to two different deformation mechanisms. For rolling degrees lower than about $70 \%$ the textures are similar to the pure copper type textures insofar as an orientation tube occurs in the same position. The density along the central line of this tube, however, markedly deviates from that of the copper texture. For rolling degrees larger than $70 \%$ a tube is no longer to be distinguished. The main feature of the texture in this deformation range is the preferred $\{011\}\langle 211\}$-orientation with a spread stretching out towards $\{011\}\langle 100\rangle$. Hence it must be concluded that in both these ranges deformation mechanisms different from one another and different from that of the copper type are operative.

According the Wassermann ${ }^{1}$, with decreasing stacking fault energy deformation twinning becomes an operative mechanism, the orientation most favourably oriented for it being (112) [111] . Accordingly, the crystallites at first move towards the same orientation tube as in the copper type by $\{111\}\langle 110\rangle$-slip. Those, however, having approached sufficiently close to the orientation (112) [11i]] are then transformed to the twin orientation (552) [1115] in the vincinity of (110) [001]. Hence, with this mechanism operative, a rudimentary orientation tube should be expected because the matrix material outside the twins behaves completely as in the copper type. This mechanism is assumed, therefore, to be operative in the low deformation range in the present results showing still some resemblance to the copper type. Hu, Cline and Goodman ${ }^{5}$ proposed another mechanism, namely, that of deformation by microtwinning which in their lower limit may degenerate into stacking faults according to the separate movement of $\{111\}\langle 112\rangle$-partial dislocations. Thus in its ultimate bounds this model corresponds to deformation and hence orientation changes according to "homogeneous" $\{111\}\langle 112\rangle$-slip. Of course, on a microscopic scale plastic deformation will never be truly homogeneous, it is rather always confined to certain active glide planes taking up all the shear with blocks of undeformed material between them. Looked upon at a scale larger than the distance of active glide planes, however, the strain may be considered homogeneous. This is the assumption underlying any "homogeneous" deformation theory.

In this approximation, the undeformed blocks between the active glide planes undergo orientation changes the magnitude of which corresponds to the shear at the boundaries averaged over a volume at least the size or larger than that of the undeformed blocks. For these considerations it doesn't matter whether the shear in the boundary regions is due to glide or twinning. Hence in the case of microtwinning the undeformed blocks of the matrix crystal between the microtwin lamellae must be assumed to rotate along with the twins according to the twin shear. This means crystal reorientation and hence texture formation must be assumed to occur according to $\{111\}\langle 112\rangle$-slip even in the case of small but finite microtwins if only the twin lamellae are closely spaced so that no $\{111\}\langle 110\rangle$ slip will occur between them. In other words the $\{111\}\langle 112\rangle$-slip model will be valid also for the untwinned matrix material if microtwinning is the predominent mode of deformation. According to results obtained by $\mathrm{Hu}$, Cline and Goodman ${ }^{5}$ with a $\mathrm{Cu}-4 \% \mathrm{Al}$ crystal in (112) [111] -orientation with this deformation mode operative the untwinned matrix material does no longer rotate towards (112) [111] . Hence in this case no rudimentary orientation tube should be expected in the polycrystal deformation texture. Hence this model is assumed valid in the high deformation range of the present results in which case there was no rudi- 
mentary orientation tube, that means no orientation density in the vicinity of $\{112\}\langle 111\rangle$. The two models discussed above, the Wassermann model and the $\mathrm{Hu}$ model must certainly be regarded as two idealized bounds with the real behaviour somewhere in between them according to the actual value of stacking fault energy. Thus for example in the Wassermann model it must be assumed that blocks of the matrix material adjacent to some twin will, to a certain extent, partake in the rotation the twin must perform in order to compensate for the antisymmetric part of its shape change. This means part of the matrix material will rotate according to $\{111\}\langle 112\rangle$-twin shear. This must be assumed to have occurred in the present investigation with the $30 \%$ rolled material. In this case there was an orientation tube similar to that of the copper type with the $\{112\}\langle 111\rangle$-orientation reduced in its density according to twinning. On the other hand, as was shown in Figure 7, the $\{110\}\langle 112\rangle$-orientation has not remained constant compared with the copper texture, rather, it exhibits an increased density. Hence the flow mechanism in the matrix material outside the twinned regions must also have been changed with respect to that of the pure copper type. This is a deviation from the "pure" Wassermann model towards the $\mathrm{Hu}$ model.

Also the $\mathrm{Hu}$ model in this idealization will not completely meet the real situation because even in the ultimate case of independent movement of $\langle 112\rangle$-partial dislocations every second dislocation moving in the same glide plane will sweep out the stacking fault, and thus give rise to $\{111\}\langle 110\rangle$ glide. Hence a certain amount of $\{111\}\langle 110\rangle$-shear is always bound to occur even in the case of vanishing stacking fault energy.

In the light of the above considerations, the Wassermann model will be an appropriate description of texture formation in the case of large twins occurring at large distances compared with the block size of the deformation microstructure. This is the range of medium stacking fault energy and low to medium degrees of deformation. The $\mathrm{Hu}$ model, on the other hand, will be effective in the case of fine dispersed microtwins which are to be expected favourably with low stacking fault energies and higher degrees of deformation. With these two models the results of the present investigation can be qualitatively understood and so can the results of a previous investigation ${ }^{7}$ concerning the rolling textures of different copper-zinc alloys for $95 \%$ rolling deformation. In this investigation the $\{112\}\langle 111\rangle$-orientation was found to be con- tinuously depleted with decreasing stacking fault energy whereas the amount of material in twin relation to this orientation, that is $\{011\}\langle 100\rangle$, passed through a maximum at about $5 \%$ zinc. This effect was explained formerly in terms of the results by Peissker ${ }^{14}$ according to which macroscopically large twins occur at medium stacking fault energy, and microscopically small ones at low energy. Hence, with decreasing stacking fault energy, the volume fraction of twins may run through a maximum and later on decrease again as it was found in this investigation. In the light of the above considerations, however, another mechanism must be discussed which may possibly be more probable. According to the $\mathrm{Hu}$ model the crystallites in the surroundings of the orientations (112) [11i] no longer rotate towards this orientation but away from it. Hence the majority of crystallites does not even reach the vicinity of (112) [11 $\overline{1}$ ] from which it twins into (110) [001]. Thus the density of twinned material in this position must be lower than that with the Wassermann mechanism being operative. Furthermore, the easier twinning becomes with decreasing stacking fault energy the farther away from the favourable orientation [112] (11ī) will it occur. Hence, the resulting twin orientations will be distributed over a much wider range. This may be the cause for the observed overall decrease in the texture severity with increasing zinc content. Finally the considerations described above may be summarized schematically in Figure 12 which shows

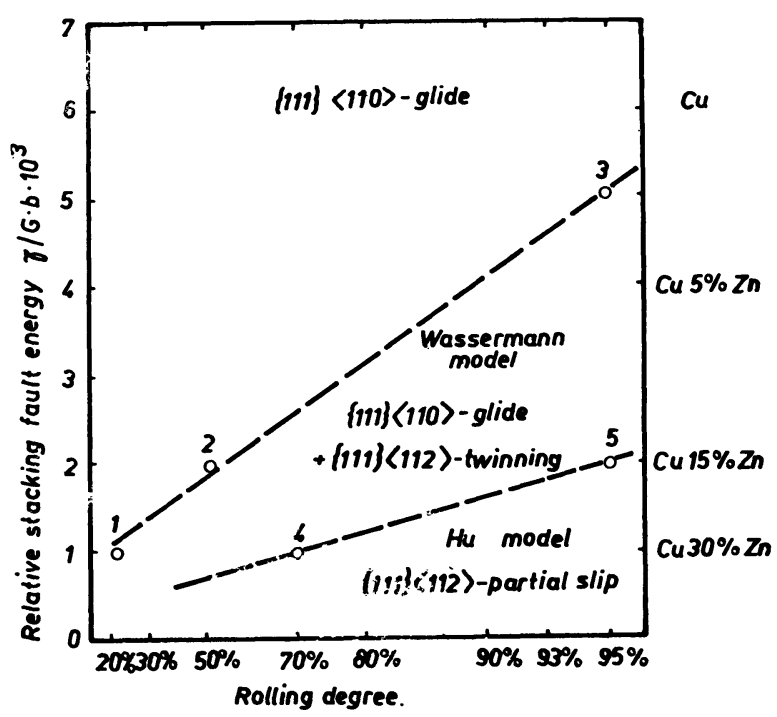

FIGURE 12 Assumed ranges of validity for different modes of deformation. 
the assumed domaines of pure $\{111\}\langle 110\rangle$-glide, of the Wassermann model and of the $\mathrm{Hu}$ model. In this Figure point 1 corresponds to the increase of stacking fault density determined by Goodman and $\mathrm{Hu}^{15}$, point 2 is taken from the paper by Leffers and Grum-Jensen ${ }^{16}$, points 3 and 5 approximately describe the concentration range in which a large amount of material in twin orientation $\{011\}\langle 100\rangle$ was found ${ }^{7}$, and point 4 is the approximate changing point in the present results. Of course, all these points are not very sharply defined, since the change from one to the other deformation mode must be assumed to occur gradually. Furthermore, it must be considered that the position of the boundaries (dashed lines) may be different in the case of deformed single crystals (compare Heye and Wasser$\operatorname{mann}^{17}$ ). The $\{111\}\langle 110\rangle$-multiple slip model has been quantified in the Taylor approximation ${ }^{18}$ by Bunge $^{19}$, and in a somewhat modified Taylor model by Leffers ${ }^{20,21}$ and by Bunge and Leffers ${ }^{22}$. The results were found to agree reasonably well with the experimentally determined orientation tube. Similar results were obtained recently by Kallend and Davies ${ }^{23}$. These authors also quantified the Wassermann model starting from homogeneous $\{111\}\langle 110\rangle$-multiple slip in the Taylor approximation to which twinning was added by introducing an empirical twinning parameter. Their results were in good agreement with experimental texture data for a copper $10 \%$ zinc alloy. In particular, they showed the presence of a rudimentary orientation tube as is to be expected from the model presented here.

\section{CONCLUSIONS}

1) The deformation texture of a cold rolled $\mathrm{Cu}-27.2 \% \mathrm{Zn}$ alloy changes from the low to the high deformation type at about $70 \%$ reduction.

2) In the low deformation range an orientation tube occurs in the same position as in the copper type but with a distinctly different density distribution along the tube axis.

3) The main feature of the high deformation type is the ideal orientation $\{110\}\langle 112\rangle$ with some spread about it in a direction different from the original tube direction.
4) A second spread range is to be observed for all rolling degrees from $\{110\}\langle 112\rangle$ towards $\{110\}$ $\langle 001\rangle$.

5) In the low deformation range, $\{111\}\langle 110\rangle$ glide and $\{111\}\langle 112\rangle$-twinning according to Wassermann are assumed to be the operative deformation modes.

6) In the high deformation range, microtwinning or $\{111\}\langle 112\rangle$-slip by partial dislocations according to $\mathrm{Hu}$, Cline and Goodman is assumed to be the most appropriate deformation model.

\section{REFERENCES}

1. G. Wassermann, Z. Metallkunde 54, 61 (1963).

2. R. E. Smallman and D. Green, Acta Met. 12, 145 (1964).

3. I. L. Dillamore and W. T. Roberts, Acta Met. 12, 281 (1964).

4. Y. C. Liu, Trans. Met. Soc. AIME 230, 656 (1964).

5. H. Hu, R. S. Cline and S. R. Goodman, in Recrystallization, Grain Growth and Textures (ASM, Metals Park, Ohio, 1966), p. 295.

6. H. J. Bunge, J. Tobisch and W. Sonntag, J. Appl. Cryst. 4, 303 (1971).

7. H. J. Bunge and J. Tobisch, J. Appl. Cryst. 5, 27 (1972).

8. J. S. Kallend and G. J. Davies, Texture 1, 51 (1972).

9. J. Tobisch and H. J. Bunge, Texture 1, 125 (1973).

10. H. J. Bunge, Mathematische Methoden der Texturanalyse (Akademieverlag, Berlin 1969).

11. I. L. Dillamore, E. Butler and D. Green, Metal Sci. J. 2, 161 (1968).

12. G. B. Harris, Phil. Mag. (VII) 43, 113 (1952).

13. J. A. Elias and A. J. Heckler, Trans. Met. Soc. AIME 239, 1237 (1962).

14. E. Peissker, Z. Metallkunde 56, 155 (1965).

15. R. S. Goodman and H. Hu, Trans. Met. Soc. AIME 242, 88 (1968).

16. T. Leffers and A. Grum-Jensen, Trans. Met. Soc. AIME 242, 314 (1968).

17. W. Heye and G. Wassermann, Forschungsbericht aus dem Institut für Metallkunde und Metallphysik der TH Clausthal 1 (1967).

18. G. I. Taylor, J. Inst. Metals 62, 307 (1938).

19. H. J. Bunge, Kristall und Technik 5, 145 (1970).

20. T. Leffers, Phys. Stat. Sol. 25, 337 (1968).

21. T. Leffers, in Textures in Research and Practice, J. Grewen and G. Wassermann eds., (Springer-Verlag, Berlin, 1968), p. 120.

22. H. J. Bunge and T. Leffers, Scripta Met. 5, 143 (1971).

23. J. S. Kallend and G. J. Davies, Phil. Mag. 25, 471 (1972). 


\section{Appendix}

TABLE I

The coefficients $C_{\AA}{ }^{\mu v}$

\begin{tabular}{|c|c|c|c|c|c|c|c|c|c|}
\hline 1 & $\boldsymbol{\mu}$ & $v$ & $30 \%$ & $50 \%$ & $70 \%$ & $80 \%$ & $90 \%$ & $93 \%$ & $95 \%$ \\
\hline 4 & $\begin{array}{l}1 \\
1 \\
1\end{array}$ & $\begin{array}{l}0 \\
2 \\
4\end{array}$ & $\begin{array}{l}-0.43 \\
-0.50 \\
-0.25\end{array}$ & $\begin{array}{l}-0.80 \\
-1.29 \\
-0.12\end{array}$ & $\begin{array}{l}-1.44 \\
-1.68 \\
-0.11\end{array}$ & $\begin{array}{l}-1.68 \\
-2.14 \\
-0.24\end{array}$ & $\begin{array}{l}-1.72 \\
-2.09 \\
-0.38\end{array}$ & $\begin{array}{l}-1.67 \\
-2.20 \\
-0.33\end{array}$ & $\begin{array}{l}-1.72 \\
-2.49 \\
-0.49\end{array}$ \\
\hline 6 & $\begin{array}{l}1 \\
1 \\
1 \\
1\end{array}$ & $\begin{array}{l}0 \\
2 \\
4 \\
6\end{array}$ & $\begin{array}{r}-2.53 \\
1.60 \\
-0.69 \\
0.08\end{array}$ & $\begin{array}{r}-1.48 \\
1.72 \\
-0.66 \\
0.00\end{array}$ & $\begin{array}{r}-1.22 \\
1.20 \\
-0.48 \\
-0.25\end{array}$ & $\begin{array}{r}-1.48 \\
1.53 \\
-0.53 \\
-0.53\end{array}$ & $\begin{array}{r}-1.89 \\
1.75 \\
-0.83 \\
-0.97\end{array}$ & $\begin{array}{r}-1.45 \\
1.27 \\
-0.73 \\
-1.03\end{array}$ & $\begin{array}{r}-1.53 \\
1.57 \\
-0.71 \\
-1.09\end{array}$ \\
\hline 8 & $\begin{array}{l}1 \\
1 \\
1 \\
1 \\
1\end{array}$ & $\begin{array}{l}0 \\
2 \\
4 \\
6 \\
8\end{array}$ & $\begin{array}{r}0.34 \\
0.28 \\
-0.22 \\
0.12 \\
0.11\end{array}$ & $\begin{array}{r}0.66 \\
0.54 \\
-0.37 \\
0.41 \\
0.14\end{array}$ & $\begin{array}{r}1.02 \\
0.56 \\
-0.28 \\
0.49 \\
0.08\end{array}$ & $\begin{array}{r}1.64 \\
0.82 \\
-0.46 \\
0.65 \\
0.07\end{array}$ & $\begin{array}{r}1.90 \\
0.92 \\
-0.56 \\
0.88 \\
-0.03\end{array}$ & $\begin{array}{r}1.82 \\
0.90 \\
-0.52 \\
0.86 \\
-0.21\end{array}$ & $\begin{array}{r}2.58 \\
1.29 \\
-0.69 \\
1.21 \\
-0.20\end{array}$ \\
\hline 10 & $\begin{array}{l}1 \\
1 \\
1 \\
1 \\
1 \\
1\end{array}$ & $\begin{array}{r}0 \\
2 \\
4 \\
6 \\
8 \\
10\end{array}$ & $\begin{array}{r}-0.10 \\
-0.06 \\
0.43 \\
-0.08 \\
0.06 \\
-0.07\end{array}$ & $\begin{array}{r}0.33 \\
-0.41 \\
0.10 \\
0.17 \\
-0.02 \\
-0.08\end{array}$ & $\begin{array}{r}0.21 \\
-0.40 \\
-0.01 \\
0.34 \\
-0.00 \\
0.09\end{array}$ & $\begin{array}{r}0.02 \\
-0.19 \\
-0.18 \\
0.56 \\
-0.04 \\
0.20\end{array}$ & $\begin{array}{r}0.15 \\
0.02 \\
-0.17 \\
0.98 \\
0.03 \\
0.51\end{array}$ & $\begin{array}{r}-0.45 \\
-0.05 \\
-0.31 \\
0.79 \\
-0.04 \\
0.44\end{array}$ & $\begin{array}{r}-0.56 \\
-0.12 \\
-0.00 \\
0.99 \\
-0.23 \\
0.61\end{array}$ \\
\hline 12 & $\begin{array}{l}1 \\
2 \\
1 \\
2 \\
1 \\
2 \\
1 \\
2 \\
1 \\
2 \\
1 \\
2 \\
1\end{array}$ & $\begin{array}{r}0 \\
0 \\
2 \\
2 \\
4 \\
4 \\
6 \\
6 \\
6 \\
8 \\
8 \\
10 \\
10 \\
12 \\
12\end{array}$ & $\begin{array}{r}-0.11 \\
-0.99 \\
0.07 \\
1.05 \\
-0.02 \\
-0.33 \\
0.03 \\
0.34 \\
-0.00 \\
-0.13 \\
0.00 \\
0.02 \\
-0.01 \\
-0.00\end{array}$ & $\begin{array}{r}-0.32 \\
-0.38 \\
-0.07 \\
0.75 \\
0.17 \\
-0.44 \\
0.03 \\
0.27 \\
-0.02 \\
-0.17 \\
-0.10 \\
-0.00 \\
-0.05 \\
-0.00\end{array}$ & $\begin{array}{r}-0.51 \\
-0.13 \\
-0.22 \\
0.30 \\
0.16 \\
-0.15 \\
-0.01 \\
0.15 \\
-0.12 \\
0.01 \\
-0.13 \\
-0.15 \\
-0.04 \\
0.00\end{array}$ & $\begin{array}{r}-1.01 \\
-0.43 \\
-0.37 \\
0.57 \\
0.29 \\
0.05 \\
0.17 \\
0.10 \\
-0.24 \\
-0.01 \\
-0.16 \\
-0.21 \\
-0.02 \\
0.04\end{array}$ & $\begin{array}{r}-1.22 \\
-0.80 \\
-0.61 \\
0.91 \\
0.49 \\
-0.39 \\
0.36 \\
0.28 \\
-0.28 \\
0.02 \\
-0.28 \\
-0.56 \\
0.20 \\
-0.12\end{array}$ & $\begin{array}{r}-1.21 \\
-0.73 \\
-0.67 \\
0.56 \\
0.41 \\
-0.16 \\
0.15 \\
0.27 \\
-0.21 \\
0.15 \\
-0.26 \\
-0.56 \\
0.18 \\
-0.21\end{array}$ & $\begin{array}{r}-1.80 \\
-0.38 \\
-1.03 \\
0.90 \\
0.48 \\
-0.17 \\
0.11 \\
0.37 \\
-0.27 \\
0.15 \\
-0.23 \\
-0.45 \\
0.30 \\
-0.24\end{array}$ \\
\hline 14 & $\begin{array}{l}1 \\
1 \\
1\end{array}$ & $\begin{array}{r}0 \\
2 \\
4 \\
6 \\
8 \\
10 \\
12 \\
14\end{array}$ & $\begin{array}{r}-0.03 \\
0.07 \\
-0.03 \\
-0.11 \\
-0.01 \\
0.04 \\
0.01 \\
0.01\end{array}$ & $\begin{array}{r}-0.11 \\
0.18 \\
0.12 \\
-0.17 \\
0.03 \\
-0.01 \\
-0.01 \\
-0.01\end{array}$ & $\begin{array}{r}-0.11 \\
0.26 \\
0.02 \\
-0.14 \\
0.02 \\
0.00 \\
0.00 \\
-0.05\end{array}$ & $\begin{array}{r}-0.25 \\
0.26 \\
0.04 \\
-0.34 \\
0.00 \\
0.08 \\
-0.00 \\
-0.05\end{array}$ & $\begin{array}{r}-0.12 \\
0.10 \\
0.07 \\
-0.43 \\
-0.05 \\
-0.17 \\
-0.12 \\
-0.21\end{array}$ & $\begin{array}{r}0.15 \\
0.44 \\
0.13 \\
-0.30 \\
0.09 \\
0.04 \\
-0.06 \\
-0.12\end{array}$ & $\begin{array}{r}0.22 \\
0.40 \\
0.01 \\
-0.50 \\
0.25 \\
0.09 \\
-0.03 \\
-0.04\end{array}$ \\
\hline 16 & $\begin{array}{l}1 \\
2 \\
1 \\
2 \\
1 \\
2 \\
1 \\
2\end{array}$ & $\begin{array}{l}0 \\
0 \\
2 \\
2 \\
4 \\
4 \\
6 \\
6\end{array}$ & $\begin{array}{r}0.04 \\
0.12 \\
-0.08 \\
-0.04 \\
0.01 \\
0.05 \\
-0.03 \\
-0.22\end{array}$ & $\begin{array}{r}0.04 \\
0.11 \\
0.03 \\
-0.17 \\
-0.06 \\
0.09 \\
0.06 \\
-0.03\end{array}$ & $\begin{array}{r}0.26 \\
0.01 \\
-0.04 \\
-0.04 \\
-0.02 \\
0.01 \\
0.04 \\
-0.03\end{array}$ & $\begin{array}{r}0.51 \\
0.18 \\
0.00 \\
-0.06 \\
-0.14 \\
-0.08 \\
-0.13 \\
-0.00\end{array}$ & $\begin{array}{r}0.71 \\
0.28 \\
0.27 \\
-0.14 \\
-0.13 \\
-0.21 \\
-0.22 \\
0.11\end{array}$ & $\begin{array}{r}0.68 \\
-0.05 \\
0.35 \\
0.14 \\
-0.22 \\
-0.15 \\
0.17 \\
0.07\end{array}$ & $\begin{array}{r}0.64 \\
-0.05 \\
0.36 \\
-0.07 \\
-0.19 \\
-0.07 \\
0.10 \\
-0.10\end{array}$ \\
\hline
\end{tabular}


TABLE I-continued

The coefficients $C_{\Omega}{ }^{\mu \nu}$

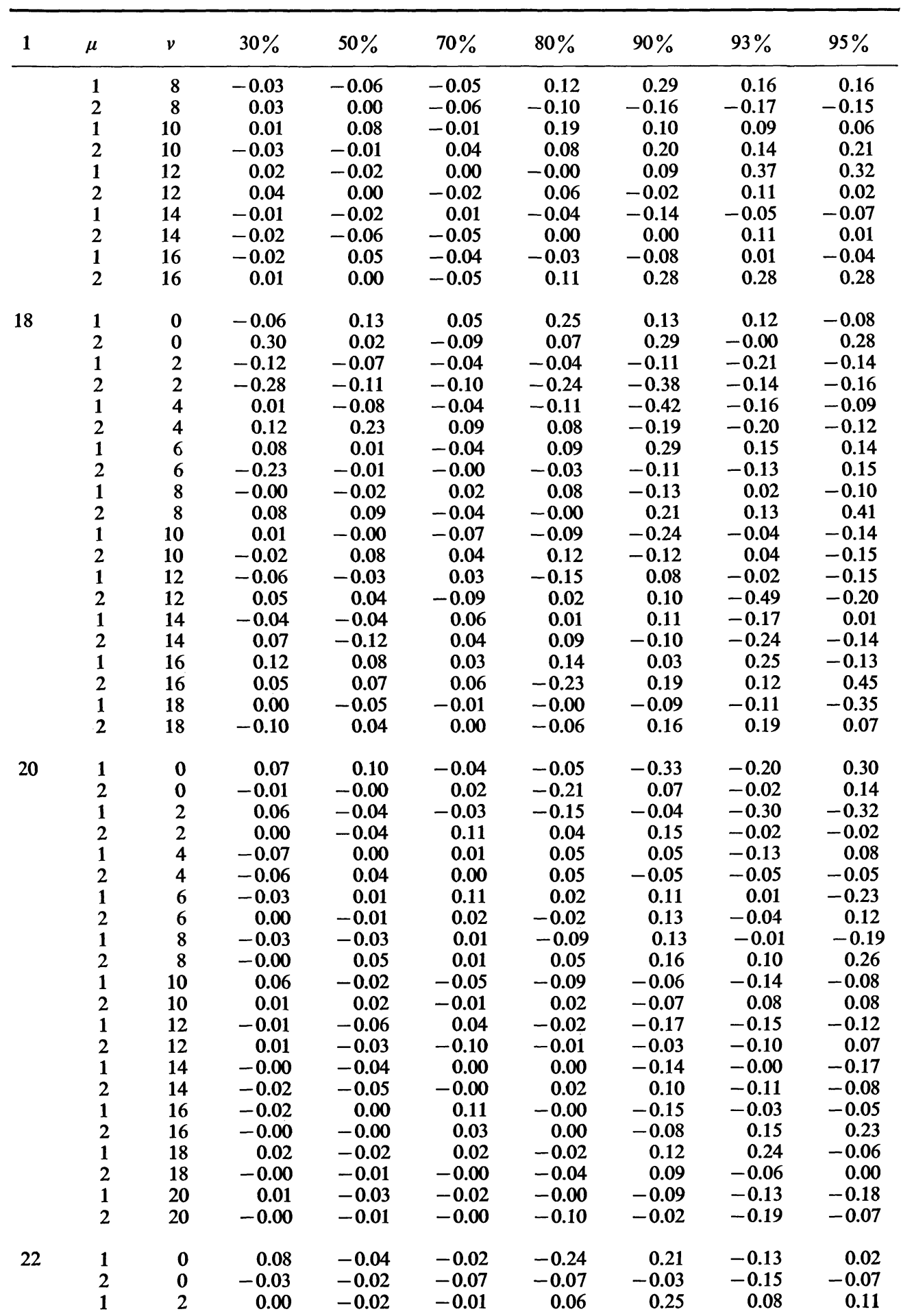


TABLE I-continued

The coefficients $C_{\Omega}{ }^{\mu \nu}$

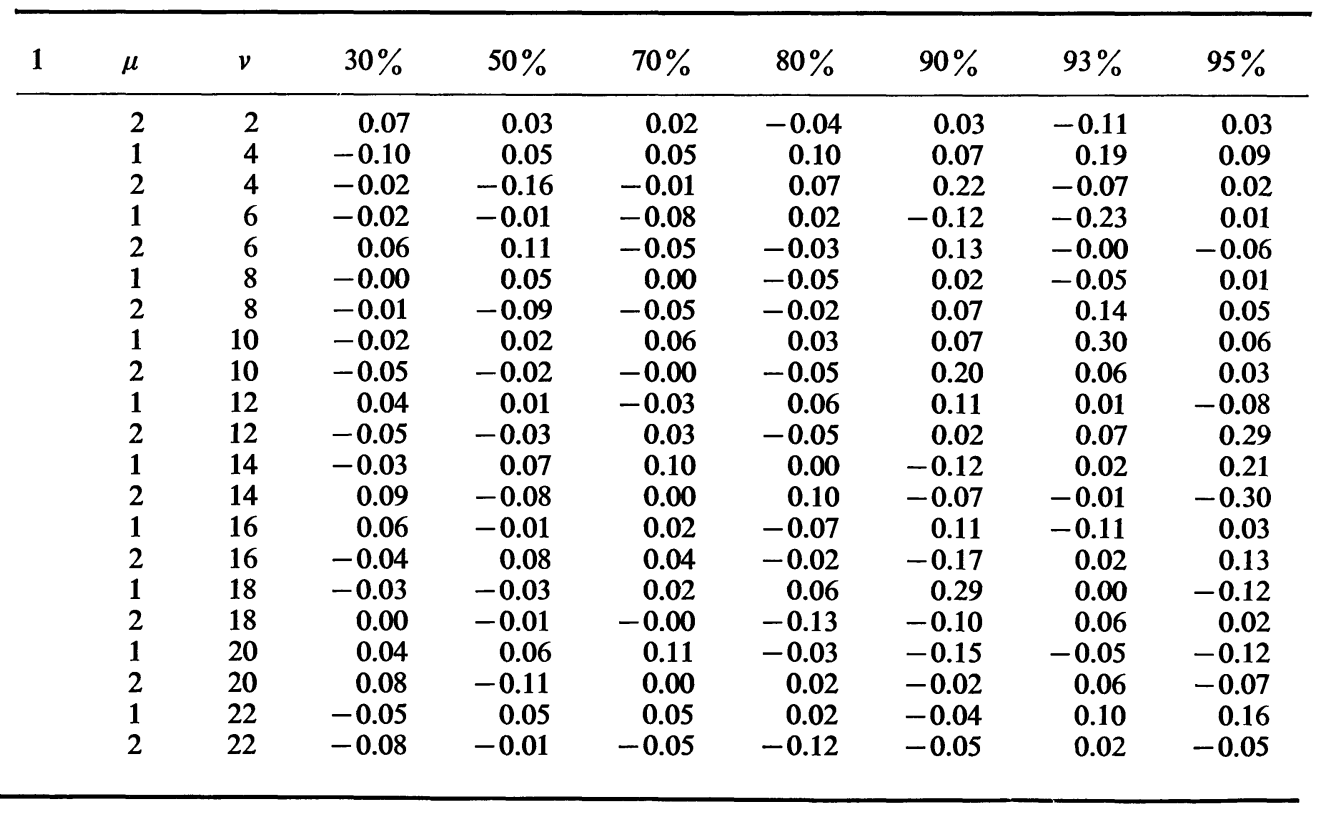

